\title{
Technology Mentoring: Research Results across Seven Campuses
}

\author{
Rachel A. Boulay ${ }^{1}$ and Catherine P. Fulford ${ }^{2}$ \\ ${ }^{1}$ John A. Burns School of Medicine, University of Hawaii, USA \\ rachel.boulay@hawaii.edu \\ ${ }^{2}$ Educational Technology, University of Hawaii at Manoa, USA \\ fulford@hawaii.edu
}

\begin{abstract}
Representatives from seven community college campuses throughout Hawaii were designated to coordinate the creation of Technology Intensive (TI) courses using a model developed at the University of Hawaii at Manoa. Data collection focused on qualitative measures: written narratives, pre and post surveys, and samples of technology products and curriculum changes. This approach allowed for the detection of subtle changes in faculty growth with regard to technology. Findings suggest that a strong mentoring program promoted substantial progress among study participants to model technology for students. Many faculty members quickly incorporated technologies into courses and promoted student use of technology in a short period of time. Participants transferred the technologies they learned with their mentor into classroom instruction and modeled the use of these technologies for their students. Technology mentoring transformed faculty into able technology users, diversifying their use of technology to accomplish specific teaching objectives.
\end{abstract}

Keywords: Institutional change, modelling, personalized learning, teacher education.

\section{Introduction}

Proposing changes in teacher education programs is a formidable task and one that educational researchers would demand to be approached in an appropriate, systematic, and informed manner. Professional development programs are tasked with trying to speed individuals through various stages of progress, as quickly as possible, while preserving the quality of instruction and the long-term adoption of a technology. Different strategies have been proposed and utilized in professional development. Arguably, certain strategies may be more effective at certain stages of development or for certain groups. However, despite the proliferation of technology-introducing strategies offered for faculty, there is not a clear understanding of such programs and their success. While a decisive answer is not currently within grasp, "mentoring" has been proposed to be a promising strategy. While this strategy may be a natural progression, our understanding of the unique qualities of mentoring programs aimed at fostering technology integration is not sufficient. The purpose of this study is to provide one 
step towards more rigorous investigation of the outcomes of mentoring programs that encourage faculty to incorporate technology into curricula.

Mentoring means to "facilitate, guide, and encourage continuous innovation, learning, and growth to prepare for the future" [1, p.13]. Thus far, the mentoring described in education has targeted professional development, while simultaneously providing social support. In this study, the mentoring relationships are characterized as skilled, progress-focused, short-term associations. The participants of this study participated in formal mentoring relationships resulting from a structured mentoring program. Mentors acted as facilitators aiming to increase the knowledge, skills, and independence of their mentees to learn and use technologies. The roles of mentors changed to respond to the needs of the mentee [2]. The literature on mentoring is clear that mentoring relationships should be systematic and planned [1], [3], [4]. Training and support for mentors is recommended. More productive and successful mentoring relationships tend to be reciprocal, where both mentee and mentor gain from the experience. Finally, the understanding of mentoring relationships suggests relationships develop in four stages: Relationship-building, Goal and expectation formation, Teaching and learning, and Reflecting and redefining roles. Programs that aim at promoting mentoring, as a form of professional development should consider these recommendations in their design and implementation, as this study did.

Recent work examines the "mentoring" that has occurred in some technology mentoring programs for faculty. Chuang, Thompson, and Schmidt [5] summarized major trends in the literature on faculty technology mentoring programs. To date, studies have predominantly relied on self-reported accounts and attitudes. Data is typically in the form of surveys or interviews. Mentoring programs have sprouted up to provide faculty professional development to incorporate newer technologies into their teaching. However, the contexts within which these programs work are very diverse. Mentoring rarely operates in a vacuum without other resources and opportunities. To begin to develop an understanding of mentoring programs, their effectiveness and complexity, detailed descriptions of the programs studied, such as has been provided in recent work [6], [7] must be provided first.

At the University of Hawaii (UH), the Department of Educational Technology (ETEC) led the College of Education (COE) in responding to the national concerns related to integrating technology into preservice teacher education. The Learning Enhancements through Innovation (LEI) Aloha Project began in 1996 and matured into a viable model for technology integration. Fulford and Ho [8] developed a model of institutional change for technology integration based on faculty mentoring. The Technology Intensive (TI) Courses Model used graduate students as "technology mentors" to assist COE faculty with technology integration [9]. The approach was based on the philosophy that teachers teach the way they are taught. Therefore, COE faculty needed to model effective technology use in their own teaching and require their students to use technology in their academic work and research.

The TI model used a systematic approach for faculty recruitment, course redesign, and evaluation to assess the integration technology into courses. A three-tiered approach was developed to meet the challenge of faculty reluctant to use technology. This method allowed faculty to work progressively towards full TI courses. The Technology Enhanced level allowed them to experience success without making great changes in their current methods. In Technology Applied Courses, faculty add the use 
of technology to the current course structure encouraging students to use technology. In Technology Intensive Courses, the faculty must follow the TI Standards and Guidelines to improve technology literacy while continuing to emphasize course content. Students have a high level of involvement and faculty serve as role models using technology.

LEI Aloha then expanded its mission so that a continuum of technology-integrated courses would be provided from the time students enter the university until they have completed their field-based student-teaching experience. At the beginning of the continuum, community college (CC) faculty members often provide prerequisite courses. They have considerable influence on how students shape their view of teaching and learning. Though the COE developed and refined a successful model, no single model can work for every institution so it needed to be modified to fit the individual differences. This paper addresses a summary of the research results that emerged across the multi-institutional initiative, given each campus' unique approaches, resources, and faculty. Inherent in the project was the idea of building a bridge between the UH CC pre-education program and the COE teacher preparation program [10], [11].

\section{Data Collection}

A total of 78 faculty participants were selected across seven unique, two-year college institutions.

\subsection{Participants}

The only public institution for higher education in the State, the University of Hawaii (UH) is a ten-campus system that includes three universities and seven CCs. Four of the CCs are on Oahu, the most populated island; the other three are on other islands of Hawaii. Approximately 24,000 students are enrolled at the system's CC degree programs. UH has a diverse student population: 49\% Asian, 22\% Caucasian, 18\% Hawaiian/Pacific Islander, and $11 \%$ other. Some faculty from every CC in Hawaii participated. The 78 faculty members (28 male, 50 female) in this study were mentored in order to increase their technology skills and their integration of technology into their courses. The females, representing two-thirds of the sample, completed 202 of the 307 total technology projects. Males completed 105 of the 307 total projects. The participants taught across a broad range of subject areas. The largest group taught English (35\%), followed Social Sciences (18\%) and Business (15\%). The other subject areas of Language, Math, Science, Medical \& Health, or Arts \& Humanities attracted 4 to 6 faculty.

\subsection{Procedures}

At the beginning of the mentoring relationship, mentors and mentees defined expectations, helped foster conversation, and clarify roles. The mentor and mentee negotiated practical issues, such as, creating a schedule and signing a contract. During early sessions, they discussed the content of the courses mentees taught and options in redesigning their curriculum. Mentors often demonstrated samples of technology curriculum samples and teaching practices. Together they would develop goals for learning and 
using technology. Goals ranged from creating an online course or class website to learning how to use a piece of equipment in their classroom or how to use specific software. Each software or hardware a faculty chose to learn was called a technology project. Multiple technology projects may have been necessary to accomplish a broader goal, such as teaching online. The pair met at least one hour a week usually in the mentee's office. During sessions, mentors helped mentees to revise course objectives, student requirements, class projects, teaching strategies, classroom activities, and instructional materials. In some cases they addressed using new mediums, such as online environments. Mentors located training materials and resources, then, designed incremental learning steps for their mentees to practice and gain confidence.

Prior to, or shortly after mentoring began, the project collected written descriptions of faculty members' technology skills and the use of technology in their courses. In most cases, the faculty member's mentor wrote these narrative descriptions. Some faculty took a pre-mentoring survey measuring their confidence on specific technologies. To corroborate this data, the project also collected course artifacts that demonstrated the faculty member's beginning technology skill level. As mentoring progressed, new or revised course artifacts were submitted that demonstrated the progress a faculty member was making on a given project. Course artifacts often included screen shots of online course pages or websites, newly created digital presentations, syllabi or handouts, student assignments, scanned work, or PDF versions of documents. These artifacts painted the picture of what of the faculty member was working on, what they were creating, and how they were revising their course. After mentoring, another written description of the faculty member's newly acquired technology skill level and the use of technology in their course were submitted. In addition, faculty completed a retrospective, self-report survey that measured their perceived increase in confidence on certain technologies using a Likert scale. The resulting data provided a plethora of information detailing a faculty member's growth on multiple technologies over time. The project received sufficient data from 78 faculty members from seven unique campuses over a period of two years. The participating faculty members primarily received either one or two semesters of mentoring during the two-year period.

\section{Analysis}

Data analysis for this qualitative research study was approached through multiple strategies [10].

\subsection{Constant Comparative Method and Triangulation}

The data was examined and reexamined to identify patterns and themes. The qualitative comparative method of data analysis [12] was used to construct categories and themes that captured the recurring patterns that emerged from comments relating to technology. The analysis was cyclical, consisting of initial coding, reflecting, and rereading, then sorting and sifting through the codes to discover patterns and themes. These methods were used to triangulate the evidence of the data [13]. Triangulation is a process that can guard against the possibility that a study's findings are simply an 
artifact of a single method, a single source, or a single investigator's biases by checking findings against other sources and perspectives [14]. In this study, methods triangulation involved validating information obtained through self-reports and narratives by checking course artifacts, examples, and documents that could corroborate what the participants reported. Using a triangulation of sources method, the data sources were compared and cross-checked to determine the consistency of different data sources within the same method. For example, multiple course artifacts, including numerous sets of instructional materials, were reviewed for each participant. The third kind of triangulation, analyst triangulation, using multiple analysts to review findings was conducted. Two individuals rated all artifacts; then, the ratings were shared with technology mentors, to provide useful member checks of the findings. By combining multiple analysts, methods, and data sources, this study provides a robust design.

\subsection{Development of Coding Instrument}

Given the naturalistic inquiry and open-ended approach to data collection, the data sources submitted for each faculty participant varied significantly. An additional strategy for data analysis was needed to strengthen the aim of a cross-institutional comparison with some reliability among multiple coders. The project developed a system for coding and synthesizing this information. Coders recorded on a form each unique technology in which a faculty member was mentored. Then, for this specific technology a notation was made of: (a) why the technology was learned, (b) what the faculty member's skill level was before and after mentoring, and, (c) whether any visible changes would be evident to students in their courses.

Unlike a limited one to five Likert scale measure, a key component was using one of the following seven descriptive categories to rate an individual faculty member's skill in using a specific technology. No Use: Although the faculty member might be aware of the given technology, he or she has never used it. Basic Use: The faculty member is aware of the technology's general capabilities and is beginning to learn the basic skills for use. Knowledge of Tools \& Features: The faculty member is moving beyond the basics of the given technology's features and is learning to use those features according his or her personal needs. Independence \& Confidence: The faculty member expresses an improved attitude or a raised confidence in his or her skills in the given technology. The faculty member's use of the technology reflects that change. He or she begins using the technology more independently and might use the technology more artfully, adventurously, or publicly, that is, for course content delivery or student communication. Additionally, he or she might begin letting students elect to use their own skills in that technology to complete course projects. Integration \& Student Use: The faculty member knows enough about the given technology to be able to apply its capabilities to student learning activities. The faculty member is able to design opportunities for students to use the technology in ways that enhance their learning or skill acquisition. Integration efforts will vary. For example, some faculty members might retrofit prior assignments to new technologies, whereas others will redesign class activities and student assignments to capitalize on technology benefits. Leadership \& Guidance: The faculty member has become an expert in the given technology. He or she is able to coach students toward individualized, creative, and exploratory uses of technology to maximize learning or enhance class projects. 
The faculty member's use might also reflect a shift in teaching philosophy or classroom methodology. Innovation: The faculty member integrates the given technology in an inventive way. He or she pushes the limits of the technology, and, invents new instructional and student uses in order to make the technology serve his or her technology needs.

\section{Results}

This study focused on one of the most promising professional development strategies advanced from the community of professionals for assisting faculty to learn technology - technology mentoring. Does this approach of professional development for faculty, personalized technology mentoring, actually lead towards achieving the goals of the national community to create technology-rich, meaningful classroom experiences for students? The following is a brief summary of numerous findings.

The 78 faculty in this study attempted and completed 307 technology integration projects. In over $67 \%(n=206)$ of these projects, faculty learned completely new software and hardware (Table 1). Over $90 \%(\mathrm{n}=279)$ of technology integration projects included software or hardware that the faculty member had no knowledge or basic knowledge in, before mentoring. Whereas after mentoring only $12 \%(n=37)$ of faculty were still reporting no knowledge or basic knowledge. After mentoring, 62\% of faculty projects $(\mathrm{n}=189)$ were classified as demonstrating technology skills at independence $(35 \%, \mathrm{n}=$ $107)$ or integration levels $(27 \%, n=82)$. An important achievement is the 13 instances of faculty's skills found at leadership or innovation levels. The data showed no instances of leadership or innovation levels among faculty before mentoring.

Table 1. Number of faculty projects at skills levels before and after mentoring

\begin{tabular}{lccccccc}
\hline & $\begin{array}{c}\text { No } \\
\text { use }\end{array}$ & $\begin{array}{c}\text { Basic } \\
\text { use }\end{array}$ & $\begin{array}{c}\text { Knowledge } \\
\text { of Tools }\end{array}$ & $\begin{array}{c}\text { Indepen- } \\
\text { dence }\end{array}$ & Integration & $\begin{array}{c}\text { Leader- } \\
\text { ship }\end{array}$ & $\begin{array}{c}\text { Inno- } \\
\text { vation }\end{array}$ \\
\hline $\begin{array}{l}\text { Before } \\
\text { mentoring }\end{array}$ & 206 & 73 & 13 & 10 & 5 & 0 & 0 \\
$\begin{array}{l}\text { After men- } \\
\text { toring }\end{array}$ & 1 & 36 & 68 & 107 & 82 & 12 & 1 \\
\hline
\end{tabular}

Approximately three-fourths (57) of the 78 faculty had one semester of mentoring and completed 226 technology integration projects. One-fourth (19) received two semesters of mentoring and completed 75 technology projects. Although fewer faculty received mentoring for two semesters, there are some interesting differences in technology skills gained between these two groups. The 78 faculty members in this study worked on a range of technology projects utilizing nearly 80 different pieces of software or hardware. These technologies were classified into 15 categories: online courseware, web design, presentation, equipment, publishing, graphics, assessment tools, file transfer, communication, internet, file management, utility, conferencing, information retrieval, and spreadsheets. Over 60 (26\%) of faculty choose to learn applications related to online courseware. Faculty also concentrated on web design 
(46.15\%), presentation (44.87\%), equipment (41.03\%), and publishing $(33.33 \%)$. Graphics, assessment tools, video, and media tools ranged from $10 \%$ to $20 \%$ of faculty's choice.

Data showed that faculty who sought to improve their technology skills through mentoring were at a beginning level. They predominantly chose to learn new technologies with which they had very little experience. Secondly, data showed that level of technology use faculty reached was substantial for all participants and campuses. The mode of technology use in the sample moved from "No Use" to "Independence \& Confidence, representing three level increments. Thirdly, data showed how technology manifested itself in the instruction for those faculty who immediately encouraged student use of technology in their courses. Approximately $60 \%$ of the participants required student use of technology after mentoring. However, only $10 \%$ of the participants exhibited use at the two higher levels of technology use, Leadership \& Guidance or Innovation. Finally, $23 \%$ of the faculty participants perceived technology use in relation to technology content standards. Unlike previous studies faculty did not omit a particular category of technology content standards, however, faculty did disproportionately target the same subset of standards.

\section{Discussion}

Each campus is different and no single professional development model is guaranteed to work at any one institution. However, through a process of transferring a working TI model, from a four-year institution to seven, very different, two-year CCs, all demonstrated success in encouraging faculty to progress in their technology skill set and to work towards better integration of technology into teaching. Faculty who had none to little knowledge in technologies gravitated to a technology mentoring program. Further, technology mentoring was fruitful in encouraging faculty to learn the newest trend with technology, such as online course development. Was the project successful? It depends. If the goal was to produce faculty who could facilitate students' individualized, creative, and exploratory uses of technology to maximize learning or enhance class projects, then no. Few faculty members were able to gain this level of skill and comfort with technology even after two semesters of mentoring. However, the evidence of growth, over two semesters compared to one, indicates that continued mentoring might increase the number of faculty achieving this level. Not a single faculty member, who taught at the community colleges in this study and was unknowledgeable about technology, was left behind in learning new technologies.

If the goal was to enable faculty to know enough about a given technology to apply its capabilities to student learning activities and design opportunities for students to use the technology in ways that enhance learning, then again, the answer is no. Although several faculty achieved this level within the study, the majority of faculty did not reach this level of integration with only one or two semesters of mentoring. Again, continued mentoring and targeting these specific skills may have a positive impact. Although, participants did immediately transfer the technologies they learned into classroom instruction and modeled the use of these technologies for their students. 
However, if the project goal was to create faculty who model learning even when it comes to the area of technology and are motivated to continue on their journey, then the answer is a resounding "YES!" The majority of faculty, even with as little as one semester of mentoring expressed an improved attitude or a raised confidence in his or her skills in the given technology. The faculty member's use of the technology reflects that change: The faculty members began to use the technology more independently, more artfully, adventurously, or publicly.

Additionally, some faculty began allowing students to elect to use their own skills in technology to complete projects. People learn at different rates, and some faculty only reached skill levels of basic or knowledge of tools with a specific technology even after one or two semesters. However, it is important to understand that these too are great strides for someone who has never used a software application, email program, or searched on the Internet. This was especially the case on campuses that focused exclusively on faculty members known to be "technophobes."

The world of technology is forever changing; so listing the particular software applications or hardware learned by faculty members may not be that useful. Even using the categories of technology does little more than paint a picture of the current trend of technology and faculty's efforts in trying to stay up-to-date. Clearly, the need to develop online materials for courses, whether they be fully online, hybrid, or simply supplemental materials, could be observed at these institutions at the time of data collection by the popularity in learning online courseware and web related programs. Interestingly, equipment issues ranging from how to work a digital still camera or a scanner to how to set-up a data projector were prominent. In the vast array of workshops offered for professional development, few focus on the nuts and bolts of connecting hardware and many involve participants at computers that are already set-up. Clearly, the faculty in this study expressed a need to learn how to hook-up equipment, synchronize it with a computer, and make it operate properly. This hands-on practical information was requested nearly as often as how to create web pages or digital slide presentations. Professional development programs should take care to address this important area of need.

Although future studies may want to consider the costs and benefits of mentoring, this study showed that mentoring faculty to integrate technology does work. No matter what level of final technology skill leveled achieved, the data is conclusive about the overall improvement by the faculty in this study. On average, the faculty moved approximately two category levels within their mentoring period, for example, from no use to knowledge of tools and features, or, from basic use to independent use. Studies should also investigate the results of long-term mentoring and the possibility of continued improvement. Individuals may assert that mentoring is expensive or inefficient, considering the heavy demands placed on human infrastructure. These individuals may argue that other professional development strategies, such as workshops or group training, can target greater numbers of individuals. However, this study points to the effectiveness of technology mentoring to 1) address all individuals, despite different learning styles, personalities, or content specialties, 2) translate into changed learning environments for students, \& 3) enable faculty to facilitate higherorder technology use by students along categories of technology standards. These outcomes achieved in only one or two semesters speak to the efficacy of using technology mentoring to enable institutions and their faculty to obtain national goals, related to technology, quickly. 


\section{Acknowledgements}

Funding for this research was provided through the following grants: US Department of Education Grant No. P336C050047 and US National Institutes of Health Grant No. RR16453 and HL073449 with matching funds from the College of Education, University of Hawaii at Manoa.

\section{References}

1. Johnson, H.: Mentoring for exceptional performance. Griffin Publishing, Glendale (1997)

2. Daloz, L.: Effective teaching, mentoring. Jossey-Bass, San Francisco (1986)

3. Daresh, J.: Leaders helping leaders: A practical guide to administrative mentoring. Corwin Press, Thousand Oaks (2001)

4. Hay, J.: Transformational mentoring: Creating developmental alliances for changing organizational cultures. McGraw-Hill, New York (1995)

5. Chuang, H.H., Thompson, A., Schmidt, D.: Faculty technology mentoring programs: Major trends in the literature. Journal of Computing in Teacher Education 19, 101-106 (2003)

6. Widmayer, S.A.: Mentoring and change: A study of the use of K12 teacher mentors to train education faculty in the integration of technology. Unpublished dissertation, George Mason University, Virginia (2004)

7. Chuang, H.H.: Sustainable faculty development: Issues in technology for teacher education. Unpublished doctoral dissertation, Iowa State University (2004)

8. Fulford, C., Ho, C.: Creating a model for technology integration through a "technology intensive" course designation. TechTrends 46(4), 11-17 (2002)

9. Eichelberger, A., Fulford, C.: Creating "technology intensive" courses through faculty mentoring. In: 23rd Annual Proceedings of Selected Research and Development Presentations of the 2001 National Convention for the Association for Educational Communications and Technology, Atlanta, Georgia (2001)

10. Boulay, R.: Faculty Mentoring Program to Incorporate New Technology into College Courses: Statewide Findings. Unpublished doctoral dissertation, University of Hawaii at Manoa (2008)

11. Rivers, R., Fulford, C., Eichelberger, A., Ho, C.: One Size Does Not Fit All: Community Colleges Uniquely Adapting A University's Model of Technology Integration. In: Proceedings for the Society for Information Technology \& Teacher Education (SITE) International Conference, Atlanta, Georgia (2004)

12. Ragin, C.: The comparative method: Moving beyond qualitative and quantitative strategies. University of California Press, CA (1987)

13. Lincoln, Y., Guba, E.: Naturalistic inquiry. Sage, Newbury Park (1985)

14. Patton, M.: Enhancing the quality and credibility of qualitative analysis. Health Service Research 34(5), 1189-1208 (1999) 